\title{
Characterization of precipitates in strip-cast $2.7 \%$ Si steel under different heat treatment conditions
}

\author{
Junsheng Mou, Haitao Jiao, Qiongqiong Han, Yuanxiang Zhang, Yang Wang, Feng Fang, Xiang Lu, \\ Zhifeng $\mathrm{Li}$, and Yunbo $\mathrm{Xu}^{\mathrm{a}}$
}

State Key Laboratory of Rolling and Automation, Northeastern University, 110819 Shenyang, China

\begin{abstract}
A $1.5 \mathrm{~mm}$ thickness as-cast $\mathrm{Fe}-2.7 \% \mathrm{Si}$ strip was produced by twin-roll strip casting and the precipitates under different isothermal holding time $(0.5 \mathrm{~min}-30 \mathrm{~min})$ and cooling rates $\left(1 \% \mathrm{~s}-20^{\circ} \mathrm{C} / \mathrm{s}\right)$ were investigated by thermal simulation experiment technology and electron probe micro-analyzer. The main precipitates in all specimens are AlN-MnS complex with a structure of core-edge. During isothermal holding, the number density of relatively large precipitates $(\geq 0.3 \mu \mathrm{m})$ decrease with increase in time and the mean size of the small precipitates $(\leq 150 \mathrm{~nm})$ increases gradually. It can be attributed to the complicated interactions of dissolve, precipitation and coarsening behavior. For precipitates in strips cooling from $1380^{\circ} \mathrm{C}$ to $20^{\circ} \mathrm{C}$, the mean size decreases continuously with increase in cooling rate because the corresponding growth rate and time of precipitates decrease. These results indicate that isothermal holding time and cooling rate have an important influence on size of precipitates in strip, which will be of great importance in optimizing properties of silicon steel.
\end{abstract}

\section{Introduction}

Silicon steels with high magnetic induction and low core loss are important soft magnetic material, which widely used for cores in motors and generators. The precipitation behavior of second phase particles, like AlN or MnS, has significant effects on grain size and magnetic properties of silicon steels by inhibiting grain growth and affecting the domain wall motion $[1,2]$. The common precipitates in conventional production process of electrical steel have been studied by Jenkins [3] and Alcantara [4] et al. In recent years, many researchers are interested in the fabrication of silicon steel by strip casting technology because of its near-net-shape casting and technical advantage. Liu [5] studied the microstructure and texture of as-cast silicon steel strip and the relative factors. In addition, Sha [6] reported the microstructural origin of strong cube recrystallization texture in non-oriented silicon steel prepared by strip casting. In addition, Song [7] researched the effects of hot rolling reduction on microstructure and texture of strip-cast grain-oriented silicon steel. These works mainly focus on the microstructure and texture evolution. However, the precipitation behavior of precipitates in as-cast strip at different conditions has not been studied systematically.

\footnotetext{
${ }^{\text {a }}$ Corresponding author: yunbo_xu@126.com
}

This is an Open Access article distributed under the terms of the Creative Commons Attribution License 4.0, which permits unrestricted use, distribution, and reproduction in any medium, provided the original work is properly cited. 
(a)

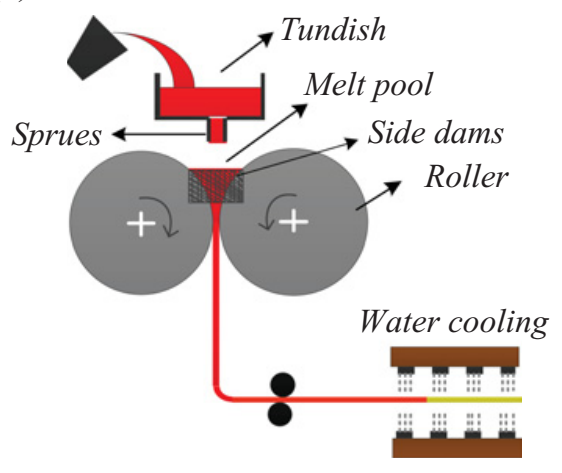

(b)

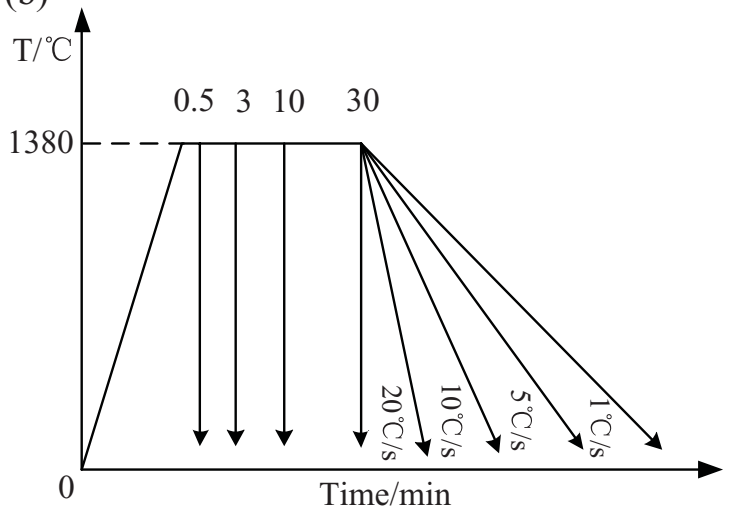

Figure 1. (a) Schematic diagram of twin-roll strip casting and (b) heat treatment schedules.

In the present work, a $\mathrm{Fe}-2.7 \% \mathrm{Si}$ strip was produced by twin-roll strip casting and subsequently subjected to high temperature heat treatment with different holding time $(0.5 \mathrm{~min}-30 \mathrm{~min})$ and cooling rates $\left(1^{\circ} \mathrm{C} / \mathrm{s}-20^{\circ} \mathrm{C} / \mathrm{s}\right)$. The purpose of this paper is to investigate the precipitation behavior of second phase particles under different holding time and cooling rates in order to optimize the size of precipitates and properties of silicon steel.

\section{Experimental procedure}

A strip of $1.5 \mathrm{~mm}$ thickness containing $0.0045 \% \mathrm{C}, 2.7 \% \mathrm{Si}, 0.272 \% \mathrm{Al}, 0.195 \% \mathrm{Mn}, 0.009 \% \mathrm{~N}$, and $0.03 \% \mathrm{~S}$ was produced by a laboratory twin-roll caster with two cast rollers of $500 \mathrm{~mm}$ diameter and $250 \mathrm{~mm}$ width. Figure 4(a) shows the schematic diagram of twin-roll strip casting process. The molten steel of $\sim 1540{ }^{\circ} \mathrm{C}$ in an induction furnace was poured into the tundish, and then flowed through the sprues into a molten pool composed by two cast rollers and side dams under Ar shield. As the rotating of rollers, the molten steel solidified into a strip which was water cooled to $\sim 900{ }^{\circ} \mathrm{C}$ and air cooled to room temperature. Some specimens were cut from the strip and subsequently subjected to high temperature heat treatment by thermal simulation experiment technology, as shown in Fig. 4(b). New specimens of $10 \mathrm{~mm} \times 8 \mathrm{~mm}$ were cut from the treated strip and etched using $4 \%$ nital. The morphologies and size distributions of precipitates in every specimen were investigated by a JEOL JXA8230F electron probe micro-analyzer equipped with an energy-dispersive X-ray spectroscopy (EDS) detector.

\section{Results and discussion}

\subsection{Precipitation under different holding time}

The optical precipitates in specimens holding for different time at $1380^{\circ} \mathrm{C}$ and quenching are shown in Fig. 2 and Fig. 3. The second phase particles mainly are AlN-MnS complex indicated by the EDS spectrum. Precipitates with two kinds of size range are observed. For the relatively large precipitates $(\geq 0.3 \mu \mathrm{m})$, Fig. 2(a) and (b) clearly show higher as compared to those in Fig. 2(c) and (d). It's to say that the number density of precipitates decreases significantly with time. However, Fig. 3(a)-(d) indicate that the main range of the smaller precipitates size $(\leq 150 \mathrm{~nm})$ increases gradually from $40-60 \mathrm{~nm}$ to $100-220 \mathrm{~nm}$ and the number density don't change significantly with increase in time. This phenomenon is related to the dynamically dissolve, precipitation and coarsening behavior of precipitates during the heat treatment. 


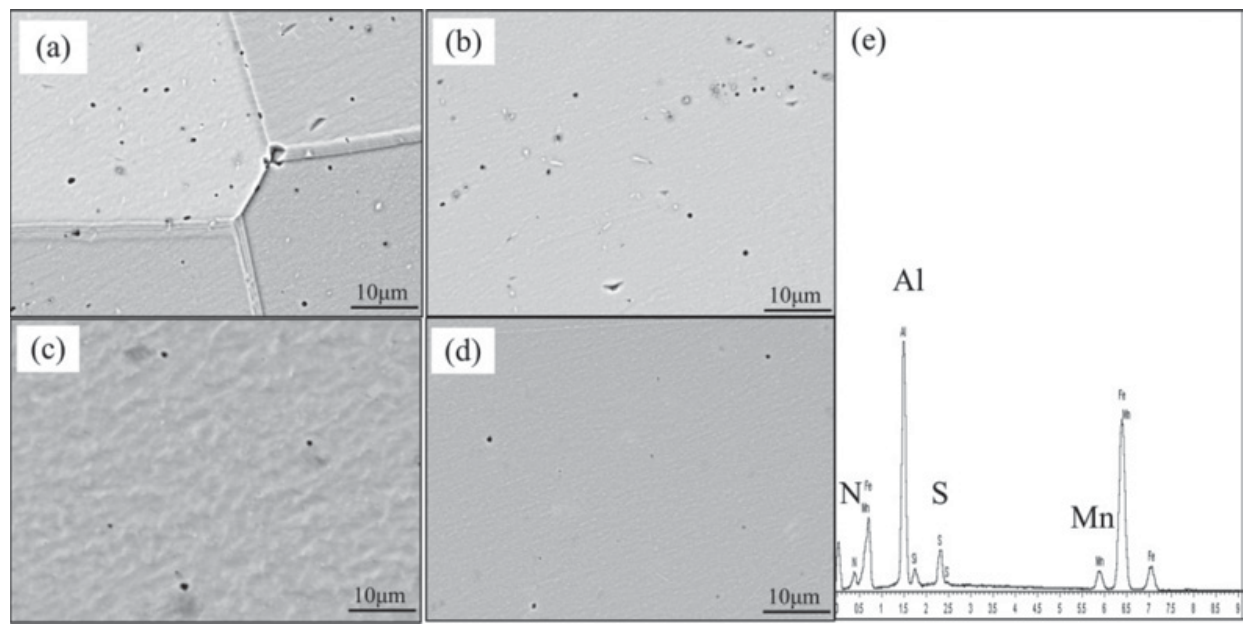

Figure 2. Morphologies of large precipitates in strips holding for (a) $0.5 \mathrm{~min}$, (b) $3 \mathrm{~min}$, (c) $10 \mathrm{~min}$, (d) $30 \mathrm{~min}$ and (e) corresponding EDS spectrum.

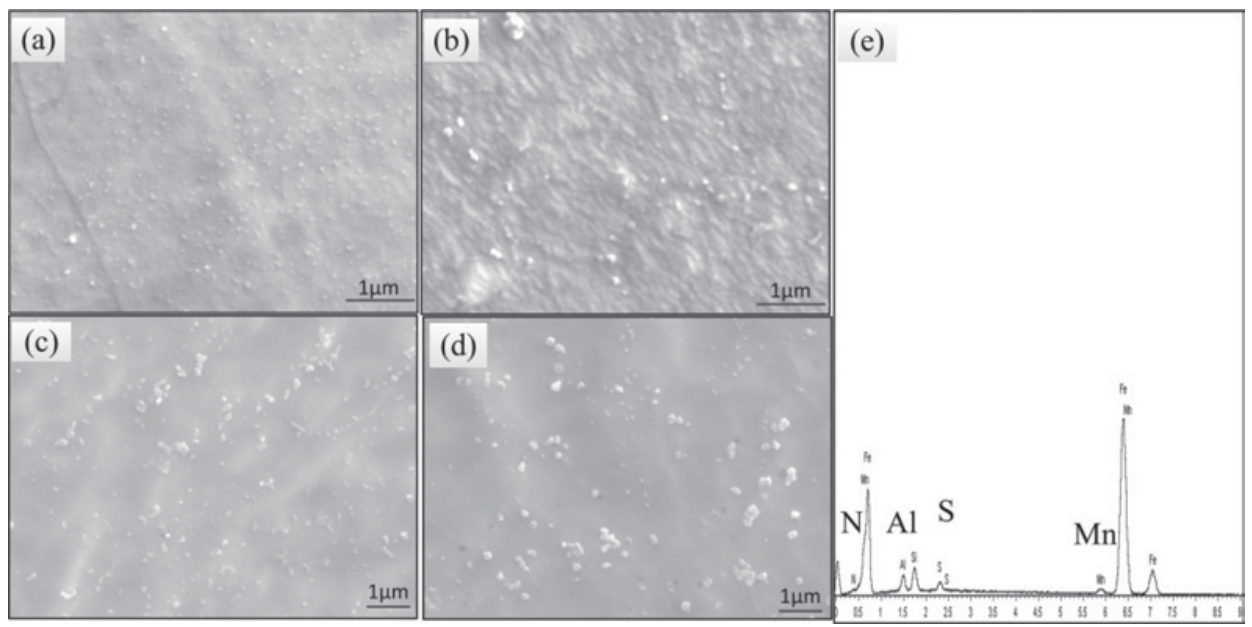

Figure 3. Morphologies of small precipitates in strips holding for (a) $0.5 \mathrm{~min}$, (b) $3 \mathrm{~min}$, (c) $10 \mathrm{~min}$, (d) $30 \mathrm{~min}$ and (e) corresponding EDS spectrum.

Darken [8] and Wriedt [9] reported individually that the solubility product of AlN and $\mathrm{MnS}$ in ferrite can be calculated according to

$$
\begin{gathered}
\log \{[A l] \cdot[N]\}=1.69-8296 / T \\
\log \{[M n] \cdot[S]\}=4.092-10590 / T .
\end{gathered}
$$

On the basis of these equations, the starting precipitation temperatures of $\mathrm{AlN}$ and $\mathrm{MnS}$ in this strip are $1656^{\circ} \mathrm{C}$ and $1402{ }^{\circ} \mathrm{C}$. When the temperature is $1380^{\circ} \mathrm{C}, \sim 19 \%$ of $\mathrm{AlN}$ and $\sim 83 \%$ of $\mathrm{MnS}$ will be dissolved in ferrite matrix at equilibrium stage. In order to reach the equilibrium of precipitation and solution, these precipitates in initial strip will begin to be dissolved during isothermal heat treatment. Eventually, the number density of large precipitates, as the initial precipitates in as-cast strip, decreases 


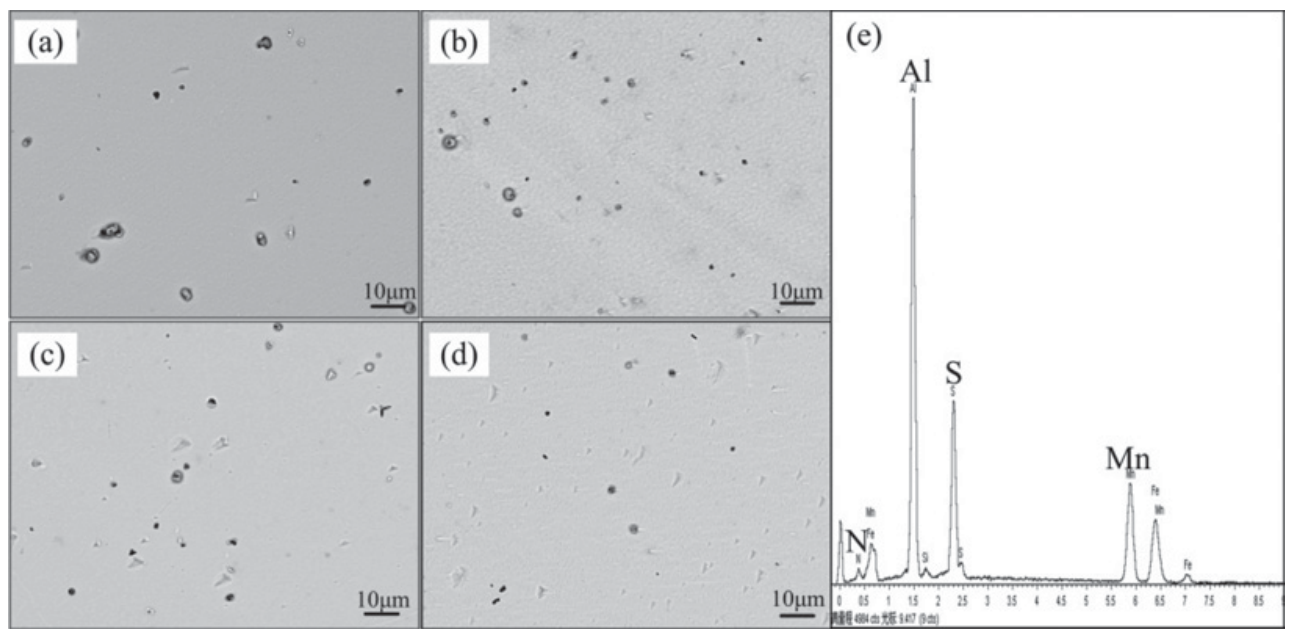

Figure 4. Morphologies of precipitates in strips cooling at a rate of (a) $1^{\circ} \mathrm{C} / \mathrm{s}$, (b) $5^{\circ} \mathrm{C} / \mathrm{s}$, (c) $10^{\circ} \mathrm{C} / \mathrm{s}$, (d) $20^{\circ} \mathrm{C} / \mathrm{s}$ and (e) corresponding EDS spectrum.

with time at $1380^{\circ}$, as shown in Fig. 2. On the other hand, some new nuclei of precipitates are formed during holding because of the solute segregation. Moreover, the defects, such as grain boundaries, subgrain boundaries and particles, will be the main nucleation sites. Then these nuclei will grow and coarsen gradually with increase in time, as shown in Fig. 3.

\subsection{Precipitation under different cooling rates}

Figure 4 shows precipitates in specimens cooled from $1380^{\circ} \mathrm{C}$ to $20^{\circ} \mathrm{C}$ at different cooling rates. The main precipitates are AlN-MnS and have various shape modes, such as rectangles, polygons and indeterminate forms. The size of precipitates at cooling rate of $1{ }^{\circ} \mathrm{C} / \mathrm{s}$ is in the range of $1.8 \sim 3.3 \mu \mathrm{m}$, while the size at cooling rate of $20^{\circ} \mathrm{C} / \mathrm{s}$ is in the range of $0.2 \sim 1.5 \mu \mathrm{m}$. By measuring precipitates size under every cooling condition, it can be seen that the mean size of AlN-MnS complex decreases with increase in cooling rate. After holding at $1380^{\circ} \mathrm{C}$ for $30 \mathrm{~min}$, a large amount of $\mathrm{MnS}$ and AlN will be dissolved in matrix. Then the $\mathrm{Al}, \mathrm{N}, \mathrm{Mn}, \mathrm{S}$ atoms can diffuse and nucleate and grow, as new fine precipitates, because of the reduced solubility during cooling process. And the rate of diffusion and growth is proportional to the temperature. That is to say, the precipitate growth rate slows gradually when temperature decreases. The time from $1380^{\circ} \mathrm{C}$ to $20^{\circ} \mathrm{C}$ reduces from 1360 s at a rate of $1^{\circ} \mathrm{C} / \mathrm{s}$ to $68 \mathrm{~s}$ at rate of $20^{\circ} \mathrm{C} / \mathrm{s}$. It means that the average rate of atom diffusion, as growth rate, is faster at $1{ }^{\circ} \mathrm{C} / \mathrm{s}$ and the time for new nuclei growth is longer. The slower growth rate and shorter growth time at faster cooling rate result in the decrease of average precipitates size.

\subsection{Complex of AIN-MnS}

Amount of AlN-MnS complex were found during the processes of isothermal holding and cooling. Figure 5 shows a typical precipitate of complex structure in specimens cooled from $1380^{\circ} \mathrm{C}$ to $20^{\circ} \mathrm{C}$ and the images of EDS elemental mapping. The results of a schematic image (Fig. 5(b)) and elemental mapping analysis images (Fig. 5(c)-(f)) clearly show that the AlN is distributed in the core part; $\mathrm{MnS}$ is distributed in the edge part. The shape of AlN is rectangle with a max length of $1.3 \mu \mathrm{m}$ and the MnS just like a spherical cap with a max diameter of $0.5 \mu \mathrm{m}$ distributed in two sides of AlN. During the cooling 


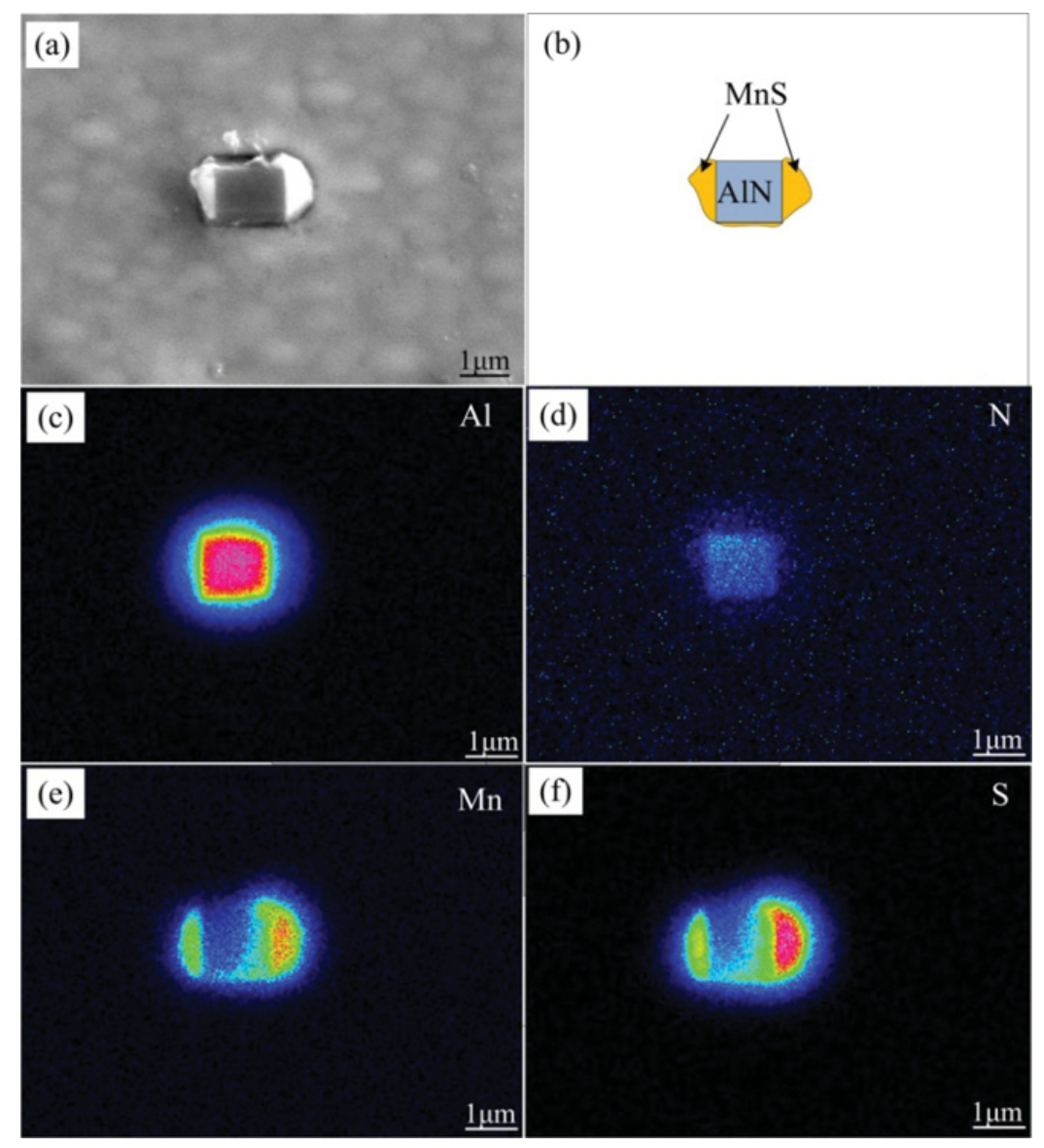

Figure 5. (a) Precipitate of AlN-MnS, (b) schematic image and (c)-(f) elemental mapping analysis image of precipitate.

process, the dissolved atoms of $\mathrm{Mn}$ and S diffuse around AlN-MnS that may have existed in strip and form the spherical cap of $\mathrm{MnS}$ which will grows gradually with time.

\section{Conclusions}

In the present work, precipitates was investigated in strip-cast $2.7 \% \mathrm{Si}$ non-oriented silicon steel subjected to different heat treatment conditions at $1380^{\circ} \mathrm{C}$. Main precipitates in all specimens are AlN$\mathrm{MnS}$ complex with a structure of core-edge. As holding time increases, the number density of relatively large precipitates $(\geq 0.3 \mu \mathrm{m})$ reduces significantly and the mean size of small precipitates $(\leq 150 \mathrm{~nm})$ increases gradually. This result indicates that both dissolve and precipitation behavior of second phase particles had happen during isothermal processes, which is a dynamic process. For precipitates in strips cooling from $1380^{\circ} \mathrm{C}$ to $20^{\circ} \mathrm{C}$, the mean size decreases when the cooling rate increases from $1{ }^{\circ} \mathrm{C} / \mathrm{s}$ to $20^{\circ} \mathrm{C} / \mathrm{s}$. This change in size can be attributed to the decrease of precipitates growth rate and time when cooling rate increases. To summary, the size of precipitates in strip can be optimized by controlling the holding time and cooling rate during heat treatments. 


\section{MATEC Web of Conferences}

This work was financially supported by the National Natural Science Foundation of China (Nos. 51174059, 51404155 and U1260204), the Fundamental Research Funds for the Central Universities (N130407003), the Program for New Century Excellent Talents in University (NCET-13-0111) and the Program for Liaoning Excellent Talents in University (LR2014007).

\section{References}

[1] G. Abbruzzese, A. Campopiano, J. Magn. Magn. Mater., 133, 123 (1994)

[2] T. Senuma, ISIJ Int., 42: 1-12 (2002)

[3] K. Jenkins, M. Lindenmo, J. Magn. Magn. Mater., 320, 2423 (2008)

[4] F.L. de Alcantara, R.A.N.M. Barbosa, M.A. da Cunha, ISIJ Int., 53, 1211 (2011)

[5] H.T. Liu, Z.Y. Liu, C.G. Li, G.M. Cao, G.D. Wang, Mater. Charact., 62, 463-468 (2011)

[6] Y.H. Sha, C. Cun, F. Zhang, D. Patel, X. Chen, S.R. Kalidindi, L. Zuo, Acta Mater., 76, 106 (2014)

[7] H.Y. Song, H.T. Liu , H.H. Lu, H.Z. Li, W.Q. Liu, X.M. Zhang, G.D. Wang, Mat. Sci. Eng. AStruct., 605, 260 (2014)

[8] L.S. Darken, R.P. Smith, E.W. Filer, Trans. AIM, 191, 1174 (1951)

[9] H.A. Wriedt, H. Hu, Matall. Trans., 7A, 711 (1976) 